\title{
Effects of Various Types of Bridge Exercise on the Walking Ability of Stroke Patients
}

\author{
Dae-Jung Ynag', Yo-Han Uhm² \\ 'Department of Physical Therapy, Sehan University, Yeongam; ${ }^{2}$ Department of Physical Therapy, Kunjang University, Gunsan, Korea
}

Purpose: The purpose of this study is to examine the effect of various bridge exercises on walking ability.

Method: The subjects were 30 stroke patients. They were divided into a bridge exercise group on a stable support surface (Group I), a bridge exercise group on an unstable support surface (Group II), and a bridge exercise group combined with whole body vibrations (Group III). 10 subjects were randomly assigned into each group. The subjects of this study had 30 minutes of nervous system physical therapy including gait training and strength training. In addition, each group underwent a 30 minutes session five times a week for eight weeks. Before intervention, LUKOtronic was used to measure step width and step length, time was measured with a $10 \mathrm{~m}$ walking test, and time and number of steps were measured with the figure 8 walking test. After the intervention, remeasured and analysis was performed for each group.

Results: As a result of comparing and analyzing the change of walking ability between groups, there was a statistically significant difference. As a result of the post hoc analysis according to the change of walking ability among groups, the change of walking ability was larger in Group III than in Group I and Group II.

Conclusion: Based on these results, it is confirmed that the bridge exercise combined with whole body vibration was more effective for walking ability. Based on these findings, this study proposes an effective program for elite athletes as well as stroke patients.

Keywords: Stroke, Bridge exercise, Walking ability, Whole body vibration

\section{INTRODUCTION}

Stroke is a neurological disorder that causes damage to brain tissue due to rupture or blockage of blood vessels that supply blood to the brain, resulting in physical disabilities. The majority of stroke patients experience a combination of various problems, including muscle weakness, abnormal muscle tension, movement patterns that limit daily life, lack of cognition and sensations, deficits in posture and balance, and impaired gait. ${ }^{1}$ In addition, it varies depending on the location, size, and cause of the damage, and neurological deficits such as hemiparalysis, visual and cognitive deficits, aphasia, motor disorder, sensory deficits, and memory impairment may occur individually or in combination. ${ }^{2}$ Stroke is a representative disease that causes damage to the central nervous system. It causes complex dysfunction depending on the damaged area such as mo-

Received Nov 4, 2019 Revised Dec 9, 2019

Accepted Dec 10, 2019

Corresponding author Yo-Han Uhm

E-mail uhmyo112@naver.com tor and sensory disorders. It also limits the performance of independent daily activities. ${ }^{3}$ Hemiparalysis, a major symptom in stroke patients, results in decreased leg strength. Weakened muscle strength decreases walking speed by decreasing balance and gait ability. ${ }^{4}$ The purpose of treatment for stroke patients is to lead independent daily lives. Their daily activities were related to balance, gait, cognition, and muscle strength, and body and leg strength exercises are needed to restore balance and gait. ${ }^{5}$

Walking can be representative of the level of human independence and quality of life. It is one of the important activities in our lives. Walking is a complex exercise in which balance, coordination, motor sensation, proprioception, joints, and muscles work harmoniously. ${ }^{6} \mathrm{~A}$ wheelchair may be an effective means if the living environment of stroke patients is flat. However, walking is the most efficient way for stroke patients because realistic environments require

Copylight $(02020$ The Korean Society of Physical Therapy

This is an Open Access article distribute under the terms of the Creative Commons Attribution Non-commercial License (https:// creativecommons.org/license/by-nc/4.o.) which permits unrestricted non-commercial use, distribution, and reproduction in any medium, provided the original work is properly cited. 
travel in a variety of environments, such as bumps, stairs, bumpy cobbled streets, lawns, and sloped streets. ${ }^{7}$ Walking is an interactive process in which the musculoskeletal and nervous systems are used collectively. Well-balanced mechanical movements occur simultaneously in several joints of the legs. This is a rhythmic movement of both legs that moves the body forward while maintaining stability during the stance phase, moving the body from one point to another. ${ }^{6}$ Walking disorders are common in stroke patients. Factors that make walking difficult are direct neurological damage associated with the lesion, secondary physical inactivity or unuse, muscle weakness, sensory loss, dystaxia, and soft tissue contracture. ${ }^{8}$ A typical change in gait showed loss of knee flexion during the stance phase, loss of the instep flexion of the ankle during the swing phase and early contact, and lack of plantar flexion during the late stance phase. ${ }^{9}$ Patients with chronic stroke reported one-third of the pace and a $40 \%$ reduction in walking distance compared to normal. ${ }^{10}$ This is because of slow movement due to poor motor control caused by nerve damage which sends an exercise command after a stroke, decreased ankle control due to non-paralytic compensatory action, lack of intrinsic sensory sensation and stiffness, and abnormal coordination between the flexor and extensor muscles of legs causing a unique walking pattern caused by simultaneous flexion or extension patterns. ${ }^{11}$

In adults, at normal walking pace, the swing phase accounts for $40 \%$ of the gait cycle and the stance phase accounts for $60 \%$. Of the $60 \%$ of the stance phase, $40 \%$ is stance phase for both legs and $20 \%$ is stance phase for a single leg. ${ }^{12}$ The typical gait features of stroke patients include asymmetrical gait patterns and slow gait speeds. In general, cadence, gait cycle, and step widths decrease, and the support of the lower limbs increases, resulting in slower speeds. They show an asymmetrical gait pattern between the paralyzed and nonparalyzed sides due to increased swing phase time in the paralyzed leg caused by deterioration of ability to move their center of gravity and increased stance phase time for the non-paralytic leg. ${ }^{13}$ The asymmetrical gait pattern is caused because a stroke patient tries to move their center of gravity to the non-paralyzed side as quickly as possible. When the stance phase starts, the heel does not touch the ground. Instead, the soles or toes touch, which shortens the stance phase on the paralyzed side and the swing phase on the non-paralyzed side. It becomes difficult to move forward, and the step length and step width decrease. ${ }^{14}$ Due to this asymmetrical gait pattern or slow walking speed, they show inefficient walking patterns that consume three to four times more energy than normal people. ${ }^{12}$ It requires muscle strength and coordination of the trunk, arm, and legs, motor sensations, proprioceptive sensations, and the interaction of joints and muscles in order to walk efficiently. Harmony between many parts is required to minimize energy consumption and move the body weight center effectively and smoothly. ${ }^{6}$ However, cerebral hemispheres damaged by stroke have problems in maintaining proper muscle tension and controlling posture and selective movement due to impairment of motor and sensory pathways and high-level integrated functions. Asymmetrical patterns appear on the paralyzed side, resulting in impaired ability to walk. ${ }^{15}$ Gait disability not only affects daily activities but also affects the quality of life, including lack of social participation.16 From the beginning, after stroke, the final goal for patients' rehabilitation is to return to society by walking. ${ }^{17}$

Bridge exercise is a common exercise for torso stability and leg strength. It is easy and simple, requiring no tools. ${ }^{18}$ The goal of bridge exercise is to prevent damage to repetitive stimulation of peripheral muscles, joints, and ligaments of the spine in daily life. It is widely used as an exercise method to increase the strength of legs and torso to improve stabilization. ${ }^{19}$ Bridge exercise is the most basic exercise that can be easily done on a mat to improve the strength of the leg joints, increase the stability of the trunk, and develop smooth movement on the mat in both a standing and sitting position. It is useful for promoting pelvic movements, the functional movements of which have an important connection in relation to walking. ${ }^{20}$ Bridge exercise is a type of closed kinetic chain exercise, which are physical exercises performed where the hand or foot is fixed and movements are performed on the body. This predominates in the contraction to the center for stabilization and increases the pressure on the joints due to the contraction of the antagonistic muscles during their exercise. It helps to promote joint stability and proprioceptive sensation. ${ }^{21}$ Bridge exercise, as a closed kinetic chain exercise, increases stability and strengthens walking ability by strengthening leg and torso muscles. ${ }^{22}$ Bridge exercise develops control in standing posture by putting weight on the legs and strengthens the trunk and leg muscles needed for walking. ${ }^{23}$ Recently, various postures for bridge exercise have been studied. In order to strengthen torso and leg muscles during bridge exercise, it is more effective to apply them on unstable support surfaces such as Swiss balls, cushions, and dy- 
namic air cushions than on stable support surfaces. ${ }^{24}$ Bridge exercise on an unstable support surface increase muscle mobilization and muscle activity, which is more effective in improving balance and gait ability. ${ }^{25}$ Exercise on an unstable support surface mobilizes more muscles than on a stable support surface and maximizes postural support muscles, increasing dynamic balance. It helps to treat and prevent injury. ${ }^{25}$ Exercise on unstable surface is a stronger exercise phase than on a stable surface, and the muscles are activated to a greater degree to maintain a stable posture. Bridge exercise on unstable support increases the activity of leg and trunk stabilizing muscles. $^{26}$

Yoo et al. ${ }^{27}$ measured torso muscle activity and balance ability after mediating bridge exercise on unstable support for 24 stroke patients. Results showed significant differences in trunk muscle activity and balance ability. Jang et al. ${ }^{28}$ stated that the bridge exercise on an unstable support surface is effective for muscle activation during bridge exercise, and there is a difference in muscle activity according to the support surface. Currently, various bridge exercises are commonly used to mediate stroke patients. However, research on the effects of various bridge exercises on walking ability is insufficient. Therefore, the purpose of this study is to provide an interventional method for efficient improvement of gait ability through various bridge exercises in stroke patients. By examining how it affects the ability to walk in stroke patients, this study wishes to provide basic data on physical therapy for stroke patients.

\section{METHODS}

\section{Subjects}

The subjects of this study were selected among hospitalized patients who were diagnosed with hemiparalysis due to a stroke for three months, from May 2019 to August 2019, and undergoing physical therapy to restore function at J Hospital in Jeonnam. Among them, patients with a hemiparalysis who had been diagnosed with a stroke not exceeding one year and who had not had a history of relapse, those who could walk $10 \mathrm{~m}$ independently with or without a brace, those who scored over 24 points in the Korean Mini-Mental State Exam (K-MMSE) and could follow and understand the oral instructions of the examiner, could communicate, had no problems with visual field defects, belong to the normal category in the motor free visual perception test, do not have other internal or surgical medical conditions, and wish to participate in this study voluntarily were selected. Thirty patients who met the criteria set in this study were classified into three groups: bridge exercise on a stable support surface (Group I), bridge exercise on an unstable support surface (Group II), and bridge exercise combined with whole body vibration (Group III). 10 subjects were randomly assigned into each group (Table 1).

\section{Method}

The subjects received 30 minutes of neurological physical therapy, which included walking training and muscle strength training. Then, Group I carried out bridge exercise using an exercise therapy mat, and Group II carried out bridge exercise using a dynamic air cushion (Aero Step, TOGU, Germany) (Figure 1). Group III performed bridge exercise using a whole body vibrator (Wellengang, GmbH, Germany) (Figure 1). The intervention was conducted for eight weeks, five times per week, and 30 minutes per day. The whole body vibrator had an amplitude of $2 \mathrm{~mm}-12 \mathrm{~mm}$ depending on the step length and a frequency of $1 \mathrm{~Hz}-25 \mathrm{~Hz}$ was applied. The amplitude and frequency are applied freely while applying the whole body vibration. Vertical vibration and side alternating vibrations are

Table 1. General characteristics of the subject

\begin{tabular}{|c|c|c|c|c|c|}
\hline & $\begin{array}{l}\text { Group I } \\
(n=10)\end{array}$ & $\begin{array}{l}\text { Group II } \\
(n=10)\end{array}$ & $\begin{array}{l}\text { Group III } \\
(n=10)\end{array}$ & $\mathrm{F}$ & $\mathrm{p}^{+}$ \\
\hline Age (yr) & $49.11 \pm 4.41$ & $50.21 \pm 5.02$ & $50.77 \pm 5.81$ & 2.98 & 0.58 \\
\hline Height (cm) & $169.76 \pm 9.91$ & $171.45 \pm 8.88$ & $170.22 \pm 9.16$ & 0.98 & 0.95 \\
\hline Weight (kg) & $68.19 \pm 7.47$ & $70.07 \pm 7.09$ & $69.95 \pm 7.77$ & 1.65 & 0.57 \\
\hline MMSE-K (score) & $27.25 \pm 2.20$ & $27.98 \pm 2.92$ & $27.44 \pm 2.85$ & 0.22 & 0.33 \\
\hline Gender (male/female) & $5 / 5$ & $6 / 4$ & $6 / 4$ & 0.84 & 0.44 \\
\hline Duration (month) & $9.51 \pm 1.20$ & $10.17 \pm 1.77$ & $10.1 \pm 1.11$ & 0.95 & 0.21 \\
\hline
\end{tabular}

Values represent mean ( \pm standard deviation), Shapiro-wilk test ${ }^{+}$, MMSE-K: mini mental state examination-Korea version, Group I : stable surface combined bridge exercise, Group II : unstable surface combined bridge exercise, Group III : whole body vibration combined bridge exercise. 

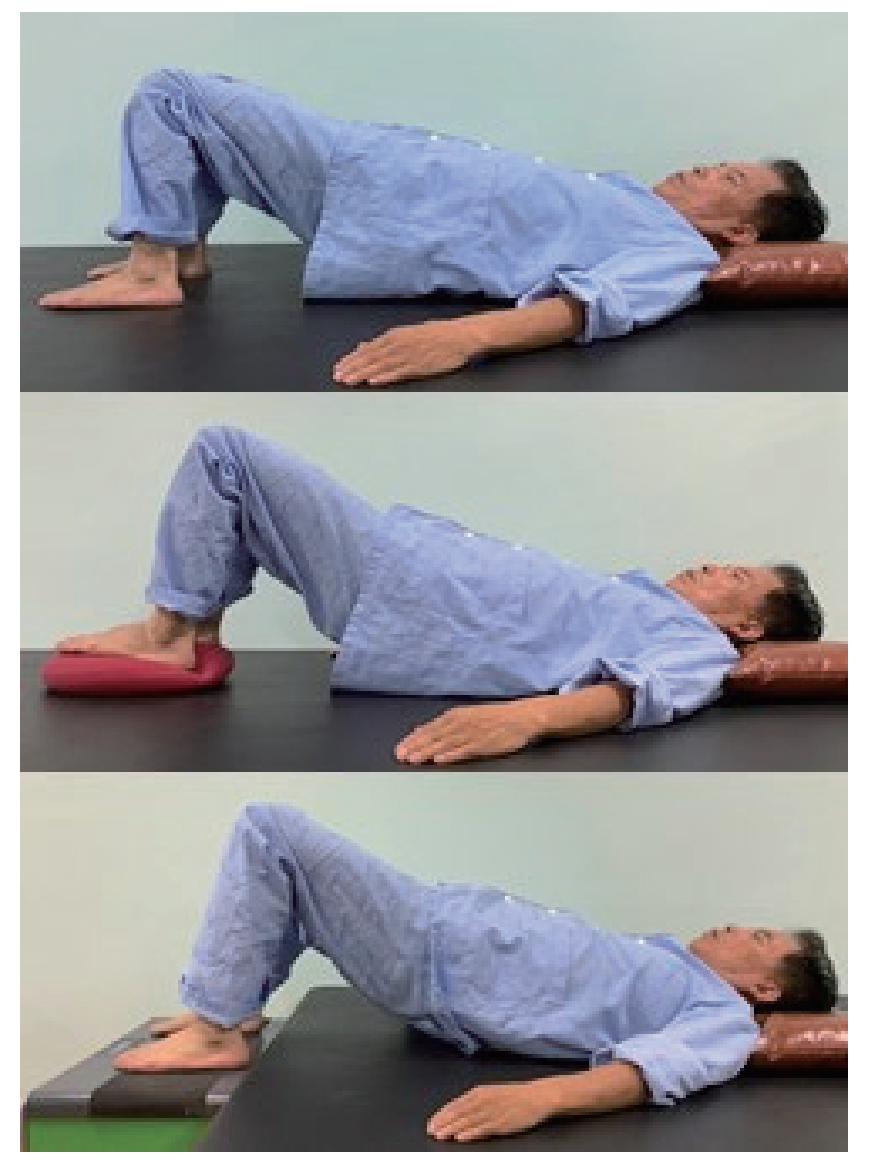

Figure 1. Bridge exercise.

mixed. For bridge exercise, the subjects had their knees bent and lying down, lowered their arms at a $30^{\circ}$ shoulder angle, $60^{\circ}$ hip flexion, $90^{\circ}$ knee flexion using the joint angle indicator and the distance between their feet matching their shoulder width. Exercise time is 30 minutes. The hip joint was kept at $0^{\circ}$ for 15 seconds, the pelvis was lowered for 10 seconds to rest. 10 sessions per set of bridge exercise and 3 sets in total we performed. The break between sets was 60 seconds. ${ }^{29}$

\section{Measurement}

\section{1) Gait analysis equipment}

In this study, the LUKOtronic (Lutz-Kovacs Electronic, Austria), a motion capture system, was used to analyze the gait of the subjects. LUKOtronic is a 3D motion capture system for analyzing kinematics variance as well as temporal and spatial variance (Figure 2). An infrared marker was attached at a designated location on the leg joint before the examination, and all subjects were allowed to walk naturally on the ground. In order to analyze the step width and step

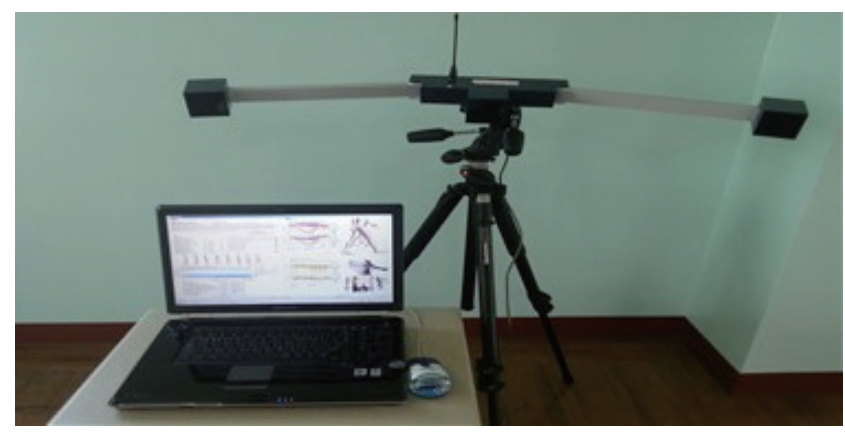

Figure 2. Figure of 8 walking test.

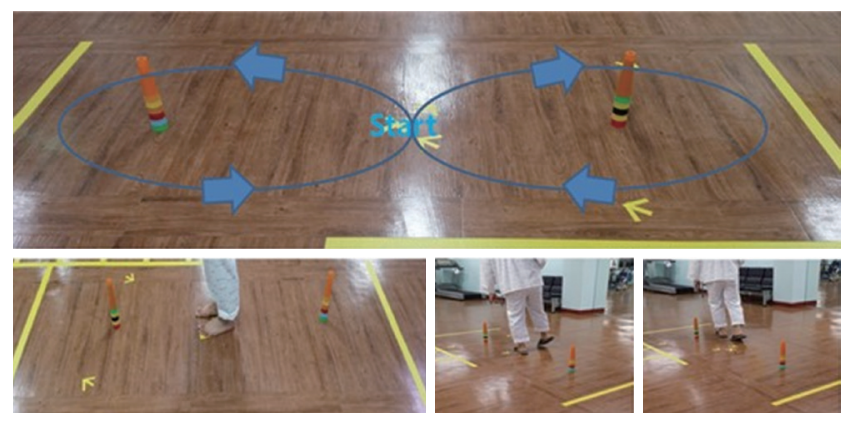

Figure 3. LUKOtronic.

length of subjects' walking performance using the LUKOtronic Motion Capture System, a three camera analysis motion system on a PC equipped with Diagnostic software for whole body gait analysis (GaitLab) was used to examine the change in walking.

\section{2) $10 \mathrm{~m}$ walking test}

The $10 \mathrm{~m}$ walking test is a tool for evaluating walking performance and has been tested for reliability and validity in various studies. The time required to move the $10 \mathrm{~m}$ distance at the subject's maximum speed was measured. To exclude the acceleration and deceleration times that appear at the beginning and end of the walking, the subject walked $14 \mathrm{~m}$ and the time for the middle $10 \mathrm{~m}$ was measured. Between the measuring points, the reliability in the measuring points is $r=0.89-1.00 .{ }^{30} \mathrm{After}$ one practice attempt, three measurements were taken and the average was recorded.

\section{3) The figure 8 walking test}

The figure 8 walking test is used to measure the walking skill of the elderly. It is an evaluation tool that measures the ability needed in everyday life that requires curved walking ability. ${ }^{31}$ After making a figure eight-shaped course with a distance between the two cones of about $1.5 \mathrm{~m}$, the upper and lower width of the 8 -shape does not ex- 
ceed about $1.2 \mathrm{~m}$, items such as time spent for one course, number of steps in progress, accuracy, and naturalness at walking are measured (Figure 3). This study used the time spent and the number of steps as the measurement items in the figure 8 walking test. As a measuring method, a stopwatch was used for the time spent. The steps were counted via slow playback after recording video.

\section{Data analysis}

SPSS Ver 25.0 for Windows was used for the data processing of this study. Shapiro-wilk testing was performed to verify normality between groups. Two-way repeated measures ANOVA was performed to compare the walking ability between groups according to the intervention method. Tukey was used for a post test. Statistical significance level was set to $\alpha=0.05$.

\section{RESULTS}

\section{Step width and step length}

As a result of comparing the step width and step length between Group I, Group II, and Group III, there was statistically significant difference $(\mathrm{p}<0.05)$. As a result of the post hoc analysis according to the change of step width and step length between groups, the change of step width and step length was larger in Group III than in Group I and Group II (Table 2).

\section{2. $10 \mathrm{~m}$ walking test}

As a result of comparing the $10 \mathrm{~m}$ walking test between Group I, Group II, and Group III, there was statistically significant difference $(\mathrm{p}<0.05)$. As a result of the post hoc analysis according to the change of $10 \mathrm{~m}$ walking test among groups, the change of $10 \mathrm{~m}$ walking test was larger in Group III than in Group I and Group II (Table 3).

\section{Figure 8 walking test}

As a result of comparing the figure 8 walking test between Group I, Group II, and Group III, there was statistically significant difference

Table 3. Comparison of 10MWT after time between subject group

\begin{tabular}{cccccc}
\hline & Pre-test & Post-test & F & p $^{+}$ & post-hoc \\
\hline Time Group I & $32.14 \pm 6.21$ & $23.41 \pm 4.07$ & & & \\
(sec) Group II & $32.77 \pm 6.56$ & $21.97 \pm 4.11$ & 3.09 & $0.021^{*}$ & । , II $<$ III * \\
Group III & $32.51 \pm 6.02$ & $19.45 \pm 4.20$ & & &
\end{tabular}

Values represent mean ( \pm standard deviation), two-way ANOVA, "Tukey, ${ }^{*} p<0.05$, Group 1 : stable surface combined bridge exercise, Group II : unstable surface combined bridge exercise, Group III: whole body vibration combined bridge exercise.

10MWT: $10 \mathrm{~m}$ walking test.

Table 2. Comparison of step width and step length between subject group

\begin{tabular}{|c|c|c|c|c|c|c|}
\hline & & Pre-test & Post-test & $\mathrm{F}$ & $\mathrm{p}^{+}$ & post-hoc" \\
\hline \multirow[t]{3}{*}{$\mathrm{SW}(\mathrm{cm})$} & Group I & $13.21 \pm 3.08$ & $10.13 \pm 2.35$ & & & \\
\hline & Group II & $13.34 \pm 2.34$ & $11.44 \pm 3.01$ & 13.954 & $0.009^{*}$ & $I,\|<\| I^{*}$ \\
\hline & Group III & $12.99 \pm 2.75$ & $11.45 \pm 2.34$ & & & \\
\hline \multirow[t]{3}{*}{$\mathrm{SL}(\mathrm{cm})$} & Group I & $24.71 \pm 3.97$ & $29.98 \pm 3.15$ & & & \\
\hline & Group II & $24.61 \pm 2.91$ & $28.01 \pm 3.64$ & 5.065 & $0.004^{*}$ & $1,\|<\| \|^{*}$ \\
\hline & Group III & $25.03 \pm 3.27$ & $27.99 \pm 3.10$ & & & \\
\hline
\end{tabular}

Values represent mean ( \pm standard deviation), ttwo-way ANOVA, "Tukey, " $p<0.05$, Group I: stable surface combined bridge exercise, Group II: unstable surface combined bridge exercise, Group III: whole body vibration combined bridge exercise.

SW: step width, SL: step length.

Table 4. Comparison of F8WT after step \& time between subject group

\begin{tabular}{|c|c|c|c|c|c|c|}
\hline & & Pre-test & Post-test & $\mathrm{F}$ & $\mathrm{p}^{+}$ & post-hoc" \\
\hline \multirow[t]{3}{*}{ Step } & Group I & $42.13 \pm 8.75$ & $37.71 \pm 8.12$ & 1.996 & $0.023^{*}$ & $\mathrm{I},\|<\| \|^{*}$ \\
\hline & Group II & $42.86 \pm 9.32$ & $39.96 \pm 8.42$ & & & \\
\hline & Group III & $42.73 \pm 9.86$ & $40.29 \pm 8.96$ & & & \\
\hline \multirow[t]{3}{*}{ Time (sec) } & Group I & $29.86 \pm 8.12$ & $22.35 \pm 8.26$ & 2.163 & $0.016^{*}$ & $\mathrm{I},\|<\| \|^{*}$ \\
\hline & Group II & $29.11 \pm 9.53$ & $26.21 \pm 9.65$ & & & \\
\hline & Group III & $30.01 \pm 8.74$ & $26.86 \pm 9.31$ & & & \\
\hline
\end{tabular}

Values represent mean ( \pm standard deviation), "two-way ANOVA, "Tukey, * $p<0.05$, Group I : stable surface combined bridge exercise, Group II : unstable surface combined bridge exercise, Group III: whole body vibration combined bridge exercise.

F8WT: figure of 8 walking test. 
$(\mathrm{p}<0.05)$. As a result of the post hoc analysis according to the change of the figure 8 walking test among groups, the change of the figure 8 walking test was larger in Group III than in Group I and Group II (Table 4).

\section{DISCUSSION}

Disorders caused by stroke generally cause limitations in performing daily activities due to functional disorders such as movement disorders, perception and cognitive disorders, and sensory disorders. ${ }^{20}$ Loss of control of the central nervous system to the paralyzed side results in muscle atrophy and muscle fiber loss, asymmetrical posture and postural control loss, abnormal balance and weight transfer ability loss, and loss of specific motor components for fine functions, which causes physical limitations in daily life. ${ }^{2}$ Normal walking refers to the process of moving the body to another place based on symmetry between legs and efficiency to minimize fatigue and stability to prevent falls or damage. ${ }^{32}$ Deformation of spatiotemporal and kinematic components occurs during the walking of stroke patients due to cardiovascular and musculoskeletal problems associated with the lesion. ${ }^{33}$ In particular, there is a difference in the step width between the paralyzed and non-paralyzed lower limbs, which is a result of the reduction of the paralytic side's single leg support time, the reduction of the hip and knee joint angles, and the increase of the ankle joint flexion angle. ${ }^{33}$ In this study, the effects of various bridge exercises on gait ability in stroke patients were examined. The goal is to suggest the possibility of a new treatment by identifying its effects through the ability to walk in stroke patients.

The study of gait analysis is to examine leg joint movement, gait characteristic variables, and changes in ground repulsive force. The biomechanical model is used to estimate the change in force and movement applied to each joint site. Also, walking is not completely understood by either kinematic analysis or kinetic analysis. It is composed of complex and diverse mechanisms that can be understood when both analyses are performed simultaneously. ${ }^{34}$ Neurological damage due to stroke affects all cycles in the hemiparalysis patient's walk, resulting in reduced and asymmetrical temporal and spatial variables. The temporal variables of gait include pace, cadence, step, step length, swing phase, stance phase, single leg support, and dual leg support. Spatial variables include step width, step length, and step width. The reduction and asymmetry of temporal and spatial variables cause decreased walking speed, dynamic balance ability, and walking endurance, which is a cause of limitations on independent mobility. ${ }^{35}$ Park $^{36}$ studied 40 patients with stroke by dividing them into two groups, a torso stabilization exercise group using a sling and a general group, mediated three times a week for 30 minutes a day for 8 weeks. The result confirmed that the torso stabilization exercise group showed significant improvement in gait ability. $\mathrm{Yeo}^{37}$ studied 6 stroke patients with bridge exercise using a sling for 4 weeks, 5 times a week, 30 minutes a day. The sling bridge exercise group showed significant improvement in gait ability. Song and $\mathrm{Kim}^{38}$ studied stroke using torso stabilization exercise on various support spaces such as ground, balls, foams of various densities, and air cushions, 3 times a week for 8 weeks. The result showed improved walking speed. In line with the previous study, this study showed significant improvement in gait ability in all bridge exercise groups. Especially when the bridge exercise was mediated on an unstable support surface such as a sling, it showed a greater effect. This is because it increases instability due to relatively inaccurate proprioception and somatosensory input on the unstable support surface, and increases the muscle activity of the surrounding muscles to secure the stability necessary for maintaining balance. ${ }^{39}$ However, among the three groups, the combination of whole body vibrations was more effective. It is assumed that the mechanical stimulation of the whole body vibration stimulates the muscle spindles and activates the trunk and leg muscles, affecting walking ability. Whole body vibration exercise is a new type of somatosensory stimulation method for the rehabilitation of stroke patients and is a safe treatment for patients with limited movement. ${ }^{40}$ Whole body vibrations are done on a vibrating platform and the body receives the vibration, stimulating the muscle belly and muscle spindles from distant parts of the muscle, delivering consistent contraction information to the spinal cord. This repetitive stimulation induces muscle contraction and relaxation, which makes the nerve roots more sensitive, increases muscle response speed, and activates the muscles and nervous system. ${ }^{41,42}$ This may result in an increase in the rate of firing of the motor nerve and allow multiple motor units can ignite simultaneously. ${ }^{43}$

$\mathrm{Sim}^{44}$ conducted a study of 15 stroke patients comparing torso stabilization exercises using central nervous system development treatment and a Swiss ball for five weeks. The result showed a significant difference in walking ability in the stabilization exercise group 
using the Swiss ball. Lee et al. ${ }^{45}$ conducted a comparative study between 20 patients with chronic stroke, divided into two groups, an isotropic torso stabilization exercise group and a general physical therapy group. There was a significant difference between the 10 meters walking test and the timed up and go test in the group using the isokinetic torso stabilization exercise. In the previous study, the torso stabilization exercise was applied, and in this study, the bridge exercise was applied. However, like the torso stabilization exercise, the bridge exercise is widely used as a stabilization program in the clinic, and can be retrained so that the gross and fine motor skills can cooperate at an appropriate ratio. ${ }^{18}$ Bridge exercise can be used to flex the torso and control the nerve roots of the extensor muscles and to strengthen the pelvic and leg muscles. It is commonly used in clinical practice as a beneficial exercise to strengthen the stability of the torso-pelvis. ${ }^{46} \mathrm{Yoo}^{47}$ conducted a comparative study for 24 stroke patients with general bridge exercise and sling-based bridge exercise. The result showed sling-based bridge exercise had significant improvement in torso and leg muscle strength. Marshall and Murphy $^{48}$ states that exercise using a therapeutic ball significantly increased muscle activity levels in the abdominal and back muscles compared to exercising on a stable support surface. Previous studies analyzed muscle activity, and this study analyzed gait ability, but many studies comparing stroke and functional activity reported that the association between muscle strength and gait ability was greater than other causes. ${ }^{49}$ In this study, it is assumed that the increase of muscle activity may affect gait ability. The higher muscle activity of the torso appeared on the unstable support surface than on the stable support surface. It was reported that when exercising on an unstable support surface, the muscles passing through the body segment will have more co-contraction than mat and exercise on a stable support surface which increase walking ability. ${ }^{50}$ It is reported that bridge exercise on an unstable support surface can lead to higher muscle activity and changes in muscular endurance and help strengthen torso and leg muscle strength. ${ }^{19}$ The bridge exercise using the unstable support surface was more effective in improving the walking ability than the general bridge exercise. Bridge exercise combined with whole body vibrations was more effective than unstable support. It has been reported that whole body vibrations activate the joint position sense receptors, stimulating the mechaonreceptors of the sole which affects the walking ability. ${ }^{51}$ Chung et al. ${ }^{52}$ analyzed the torso stabilization exercise group and general physical therapy group for 19 stroke patients. The result showed that there were significant effects on step width and step length in the torso stabilization exercise group. In this study, there were also significant differences in step width and step length in all groups, but the group utilizing whole body vibration showed a significant improvement over the other two groups. One limitation of this study is that the subject's daily life was not controlled, which may have affected the results of the experiment. An additional limitation is that, in selecting subjects, they were limited to a specific region. This study was conducted to examine the effects of various bridge exercises on the walking ability of stroke patients. For stroke patients, general bridge exercise, bridge exercise on an unstable support surface, and bridge exercise combined with whole body vibrations were utilized for 8 weeks. Upon evaluating their ability to walk, all three groups showed significant improvements in step width and step length, 10 $\mathrm{m}$ walking test, and the figure 8 walking test. However, the bridge exercise combined with whole body vibrations group showed statistically significant improvement compared to the other two groups. This study confirmed that various bridge exercise interventions have positive effects on walking ability in stroke patients. In particular, it was confirmed that bridge exercise using whole body vibration could be an effective treatment method for walking ability. In addition, it could be used as an effective program when applied to not only patients with central nervous system damage but also to normal people and athletes. Based on this research, more systematic evaluations and studies are required in addition to this study, which only analyzed the ability to walk.

\section{ACKNOWLEDGEMENTS}

The research was conducted by the research grant of Se $\neg$ han university in 2020 .

\section{REFERENCES}

1. Harris JE, Eng JJ, Marigold DS et al. Relationship of balance and mobility to fall incidence in people with chronic stroke. Phys Ther. 2005;85(2):150-8.

2. Lundy-Ekman L. Neuroscience: Fundmentals for rehabilitation. 4th. Amsterdam, ELSEVIER Saunder. 2007.

3. Peurala SH, Könönen P, Pitkänen K et al. Postural instability in patients with chronic stroke. Restor Neurol Neurosci. 2007;25(2):101-8.

4. Yang YR, Chen YC, Lee CS et al. Dual task related gait changes in indi- 
viduals with stroke. Gait \& Posture. 2007;25(2):185-90.

5. Hagovská M, Olekszyová Z. Relationships between balance control and cognitive functions, gait speed, and activities of daily living. Z Gerontol Geriatr. 2016;49(5):379-85.

6. Perry J, Burnfield JM. Gait analysis: normal and pathological function. J Sports Sci Med. 2010;9(2):353.

7. Lee JY, Park JS, Lee DH et al. Effect of the trunk muscle stabilization training on balance for chronic stroke patients. JKAIS. 2012;13(3):1212-9.

8. Kelly JO, Kilbreath SL, Davis GM et al. Cardiorespiratory fitness and walking ability in subacute stroke patients. Arch Phys Med Rehabil. 2003;84(12):1780-5.

9. Bensoussan L, Mesure S, Viton JM et al. Kinematic and kinetic asymmetries in hemiplegic patient's gait initiation patterns. J Rehabil Med. 2006;38(5):287-94.

10. Pang MY, Eng JJ, Dawson. A community based fitness and mobility exercise program for older adults with chronic stroke: a randomized controlled trial. J Am Geriatr Soc. 2005;53(10):1667-74.

11. Sakuma K, Ohata K, Izumik K et al. Relation between abnormal synergy and gait in patients after stroke. J Neuroeng Rehabil. 2014;25(11):141.

12. Lamontagne A, Stephenson JL, Fung J. Physiological evaluation of gait disturbances post stroke. Clin Neurophysiol. 2007;118(4):717-29.

13. Allen JL, Kautz SA, Neptune RR. Step length asymmetry is representative of compensatory mechanisms used in post-stroke hemiparetic walking. Gait \& Posture. 2011;33(4):538-43.

14. Ford MP, Wagenaar RC, Newell KM. Arm constraint and walking in healthy adults. Gait \& Posture. 2007;26(1):135-41.

15. Ramas J, Courbon A, Roche F et al. Effect of training programs in adult stroke patients: literature review. Annales de readaptation et de medicine physique. 2007;50(6):438-44.

16. Studenski S, Perera S, Patel K et al. Gait speed and survival in older adults. JAMA. 2011;305(1):50-8.

17. Lord SE, Rochester L. Measurement of community ambulation after stroke current status and future development. Stroke. 2005;36:1457-61.

18. Stevenson VK, Coorevits PL, Bouche KG et al. The influence of specific training on trunk muscle recruitment patterns in healthy subjects during stabilization exercises. Manual Therapy. 2007;12(3):271-9.

19. Kisner C, Colby LA, John B. Therapeutic exercise: foundations and techniques. 6th ed. Philadelphia, FA Davis Company. 2018.

20. O'sullivan SB, Schmitz TJ, Fulk G. Physical rehabilitation. 7th ed. Philadelphia, FA Davis Company. 2019.

21. Bae JY. The effect of bridging exercises featuring various knee-joint angles on balance and muscle activity. Namseoul University. Dissertation of Master's Degree. 2014.

22. Song GB, Heo JY. The effect of modified bridge exercise on balance ability of stroke patients. J Phys Ther Sci. 2015;27(12):3807-10.

23. Youdas JW, Hartman JP, Murphy BA et al. Magnitudes of muscle activation of spine stabilizers, gluteals, and hamstrings during supine bridge to neutral position. Physiother Theory Pract. 2015;31(6):418-27.

24. Feldwieser FM, Sheeran L, Meana-Esteban A et al. Electromyographic analysis of trunk-muscle activity during stable, unstable and unilateral bridging exercises in healthy individuals. Eur Spine J. 2012;21(2):S17186.

25. Lehman GJ, Hoda W, Oliver S. Trunk muscle activity during bridging exercises on and off a swiss ball. Chiropr Osteopat. 2005;30:14.
26. Imai A, Kaneoka K, Okubo Y et al. Trunk muscle activity during lumbar stabilization exercise on both a stable and unstable surface. J Otrthop Sports Phys Ther. 2010;40(6):369-75.

27. Yoo JS, Jeong JR, Lee WH. The effect of trunk stabilization exercise using an unstable surface on the abdominal muscle structure and balance of stroke patients. J Phys Ther Sci. 2014;26(6):857-9.

28. Jang EM, Kim MH, Oh JS. Effects of a bridging exercise with hip adduction on the EMG activities of the abdominal and hip extensor muscles in females. J Phys Ther Sci. 2013;25(9):1147-9.

29. Czaprowski D, Afeltowicz A, Gębicka A et al. Abdominal muscle EMGactivity during bridge exercises on stable and unstable surfaces. Phys Ther Sport. 2014;15(3):162-8.

30. Dean CM, Richards CL, Malouin F. Task-related circuit training improves performance of locomotor tasks in chronic stroke: a randomized, controlled pilot trial. Arch Phys Med Rehabil. 2000;81(4):409-17.

31. Hess RJ, Brach JS, Piva SR et al. Walking skill can be assessed in older adults: validity of the Figure of 8 walk test. Physical Therapy. 2010;90(1):8999.

32. Pelton TA, Johannsen L, Huiya Cet al. Hemiparetic stepping to the beat: asymmetric response to metronome phase shift during treadmill gait. Neurorehabil Neural Repair. 2010;24(5):428-34.

33. Jung T, Lee D, Charalambous C. The influence of applying additional weight to the affected leg on gait patterns during aquatic treadmill walking in people poststroke. Arch Phys Med Rehabil. 2010;91(1):129-36.

34. Levangie PK, Norkin CC. Joint structure and function: a comprehensive analysis. 5th ed. Philadelphia, FA Davis Company. 2011.

35. Chen G. Pattern C. Treadmill training with harness support: selection of parameter for individuals with post-stroke hemiparesis. J Rehabil Res Dev. 2006;43(4):485-98.

36. Park JH. The Effects of trunk stabilization exercise using sling on upper extremity function and balance in patients with chronic stroke. Dissertation of Master's Degree. Daegu University. 2011.

37. Yeo KD. The effects of trunk stabilization exercise using sling on upper extremity function and balance in patients with chronic stroke. Daegu university. Dissertation of Master's Degree. 2019.

38. Song JM, Kim SM. The effect of trunk stability exercise on balance and gait in stroke patients. Journal of the Korean Society of Physical Medicine. 2010;5(3):413-20.

39. Lee SC, Kim TH, Cynn HS et al. The influence of unstability of supporting surface on trunk and lower extremity muscle activities during bridging exercise combined with core-stabilization exercise. Phy Ther Korea. 2010;17(1):17-25.

40. Mikhael M, Orr R, Fiatarone SMA. The effect of whole body vibration exeposure on muscle or bone morphology and function in older adults: a systematic review of the literature. Maturitas. 2010;66(2):150-7.

41. Cardinale M, Bosco C. The use of vibration as an exercise intervention. Exercise and Sport Sciences Reviews. 2003;31(1):3-7.

42. Zaidell LN, Mileva KN, Sumners DP. Experimental evidence of the tonic vibration reflex during whole body vibration of the loaded and unloaded leg. PLoS ONE. 2013;8(12):e85247.

43. Sanudo B, Feria A, Carrasco L. Does whole body vibration training affect knee kinematics and neuromuscular control in healthy people?. J Sports Sci. 2012;30(14):1537-44.

44. Sim HB. The effect of lower trunk stabilization exercise on muscle activ- 
ity, balance and gait in patients with hemiplegia. Dissertation of Master's Degree. Gachon University. 2012.

45. Lee GC, Kang HG, Lee SM. The effect of isokinetic trunk exercise for strength, gait and balance in the patients with chronic stroke. Journal of Special Education. 2010;49(3):199-218.

46. Koshiro H, Michiyuki K, Tomoyoshi O. Effect of core stability training on trunk function, standing balance, and mobility in stroke patients: a randomized controlled trial. Neurorehabilitation and Neural Repair. 2016;31(3):240-9.

47. Yoo JW. The effect of bridge exercise using sling on a stroke patient's trunk and lower limb muscle activity. Sahmyook University. Dissertation of Master's Degree. 2016.

48. Marshall PW, Murphy BA. Core stavility exercises on and off a Swissball. Arch Phys Med Rehabil. 2005;86(2):242-9.
49. Lin S. Motor function and joint position sensein relation to gait performance in chronic stroke patients. Arch Phys Med Rehabil. 2005;86(2):197203.

50. Granacher U, Gollhofer A, Stras D. Training induced adaptations in characteristics ofposturalreflexes in elderly men. Gait Posture. 2006;24(4):45966.

51. Moezy A, Olyaei G, Hadian M. A comparative study of whole body vibration training and conventional training on knee proprioception and postural stability after anterior cruciate ligament resconstruction. Br J Sports Med. 2008;42(5):373-8.

52. Chung EJ, Lee BH, Hwang SJ Core stabilization exercise with real-time feedback for chronic hemiparetic stroke: a pilot randomized controlled trials. Restorative Neurology and Neuroscience. 2014;32(2):313-21. 